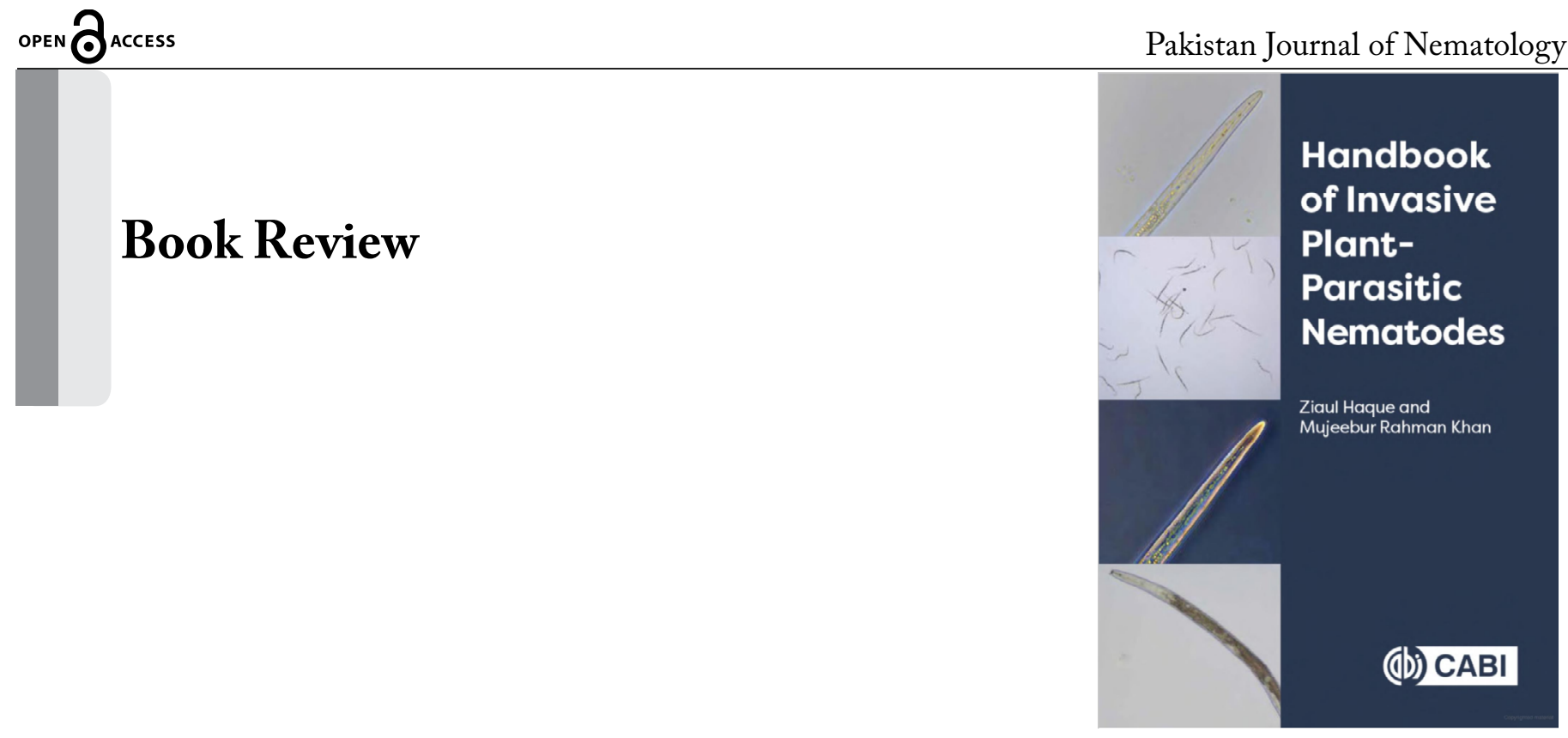

\title{
Ziaul Haque and Mujeebur Rehman Khan, Invasive Plant Parasitic Nematodes, ISBN-13: 9781789247367 (hardback); 9781789247374 (ePDF); 9781789247381 (ePub) Open Access, https://dx.doi. org/10.1079/9781789247367.0000
}

\author{
Reviewed by Dr. Zafar A. Handoo Mycology \& Nematology Genetic Diversity \& Biology Laboratory, \\ USDA, ARS, Northeast Area, Bldg. 010A, Rm. 111, BARC-West, 10300 Baltimore Avenue, Beltsville, \\ MD 20705, USA; Email: zafar.handoo@ars.usda.gov \\ https://dx.doi.org/10.17582/journal.pjn/2021.39.2.156.157
}

Over the last century, nematode awareness and nematology have evolved in tandem, with agricultural trends like monoculture increasing the yield-limiting impact nematodes have had on vital crops. Universities, independent research institutions, and companies all across the world have gained and multiplied nematology competence. Because nematode biology is influenced by a variety of circumstances, a comprehensive understanding of agricultural systems is required to adopt management measures. The goal of this book is to educate practitioners, professionals, scientists, researchers, students, and government officials working on plant quarantine and biosecurity with reference to plant parasitic nematodes with fundamental and advanced knowledge on invasive nematodes from a worldwide viewpoint. This book provides a worldwide perspective by giving 17 chapters that explain over 100 nematodes and their potential threats in various regions. Authentic identification, geographical distribution, risk of introduction, host range, symptoms, biology, and ecology, planting ma- terial liable to carry the nematodes and their vector, if any, chance of establishment, likely impact, phytosanitary measures, and a detailed account of diagnostic procedures such as sampling, isolation/detection, and identification with morphological and molecular characterization are all included for each nematode entry.

The book has been created to focus on the principle of the Convention on Biological Diversity (CBD), which states that an invasive alien species is one whose introduction and/or spread endangers biological diversity (CBD, 2002). The pest risk analysis framework is used to develop common assessment criteria for nematode invasiveness (ISPM 11, 2016). The Commission on Phytosanitary Measures (CPM), which is the IPPC's regulatory body, adopts International Standards for Phytosanitary Measures (ISPM). The propagated pressure, based on the size and frequency of introductions; abiotic factors, incorporating ecosystem invisibility based on physical con- 
ditions; and biotic factor (PAB), which includes the characteristics of invading species, recipient communities, and their interactions are key matters of discussion of this book. Adaptability to soil edaphic factors, distribution (native or non-invasive origin), survival adaptation, wide host range, life cycle, fecundity and multivoltine nature, dispersal rate, and invasive pathways, persistence, and competition are all important characteristics of invasive nematode species that are explained in detail for each included nematode species. Therefore, the theme of this book is within the lines of ISPM.

The authors' purpose, as stated in the prologue, was to create a book on plant-parasitic nematodes that would appeal to a wide audience, particularly those studying the subject at the undergraduate and postgraduate levels; I feel they accomplished this brilliantly. 